\title{
Tattua
}

JOURNAL OF PHILOSOPHY

\section{WHITEHEAD AND PARTICLE -WAVE DUALITY: A CRITICAL STUDY FROM THE PERSPECTIVE OF SYSTEM PHILOSOPHY}

\section{Luke George}

\section{Introduction}

There is a raging controversy about the applicability of process philosophy, as developed by Alfred North Whitehead (1861-1949), to the quantum phenomena with particle-wave duality'. This issue is aggravated by the fact that the substance approach, which Einstein famously advocated, has failed to suggest an alternative philosophy for explaining the dual aspecis of subatomic world. In this context, the present article first examines the essential features of the rival positions of Whitehead and Einstein with regard to space-time relativity. Then we will see that their difference has a philosophical counter part in the conflict between instrumentalism and scientific

1. Robert John Russell, Barbour's Assessment of the Philasophical and Theological implications of Physics and Cosmology, in Robert John Russell (Editor), Fitty years in Science and Religion - Ian G. Borbour and his Legacy, (Ashgate Publishing Lid, England and USA, 2004), referred hereatter by the acronym FYSR, pages 145.149. John B Cobb Jr. God and Physics in the Thought of Ian Barbour, in FYSR, pp. 261-264. 
realism. The issue boils down to the fundamental question: What is the reality of physical world having particle-wave duality?

The later part of this paper introduces the theory of dualist reality, which forms the core of System Philosophy, which can synthesize instrumentalism and scientific realism. It provides a comprehensive epistemology reconciling the controversies about the justification of quantum physics.

\section{Whitehead's Process View of Quantum Physics}

In 1905, Whitehead wrote a paper entitled On Mathematical Concepts of the Material World, which 'undertook the unification of geometry and physics by means of the powerful new tool - symbolic logic - which was being forged by Whitehead and Russell between 1900 and $1910^{\prime 2}$. Subsequently, Whitehead elaborated and discussed thoroughly the seminal ideas of the 1905 paper in the three books, The Principles of Natural Knowledge (1919), The Concept of Nature (1920) and The Principle of Relativity (1922). In these books, he proposes the theories of the physical world in terms of mathematical logic of relations.

Posing the fundamental question "how can a point be defined in terms of lines?", Whitehead searched for o new foundation of physics. If we perceive relations in the form of straight lines, then a point (representing a material particle) is the point of intersection of two or more lines. So the points (particles) and geometrical figures (material bodies) are ultimately reduced to symbolic logic. It avoids the assumption that material particles exist fundamentally.

Whitehead realized that the mechanistic worldview of Newton and Einstein involves the "bifurcation of nature", where bifurcation means the distinction between nature as sensed and nature as postulated by scientific theory ${ }^{3}$. Newtonian concepts of space and time involve this separation between the subjective idea of mind and the postulated idea of physics.

Instead of treating particles as postulated physical objects, Whitehead describes particles as symbolic concepts which are immediately sensed (ideas in the subject mind). In this manner the bifurcation of noture does not occur, since the only

2. Paul F. Schmidi, Perception and Cosmology in Whitehead's Philosophy (Rutgers University Press, New Jersey, 1967), p. 4.

3. Filmer S. C. Northrop, Whitehead's Philosophy of Science, in Paul Arhur Schilpp (editor), The Philosophy of Alfred North Whiteheod (Northwestern Universily, 1941). p. 168. 
entitles which physics deal with are the immediately sensed symbolic concepts, which are alternatively called as 'events's. A material particle is just an event in four dimensional space-time formed by straight lines. In this manner, Whitehead sought to describe the natural world in terms of events in space-time, which are immediately sensed as symbolic objects. This doctrine of relativity of space and time is called phenomenal relational theory of space and time $e^{5}$. Here space and time are defined using the phenomenal relations between symbolic objects like straight lines.

We can observe that the forgoing theory of Whitehead differed sharply from Einstein's Special Theory of Relativity (1905) and General Theory of Relativily (1916). Einstein proposed the relativity of space and time and accepied the classical view about the existence of matter. In the mathematical language of Einstein, the relativity of space and time means that the moving particles are in relative motion within the spacetime continuum. Space and time are external relations in respect of moving particles. The physical relational theory of space and time, which Einstein proposed in 1916 , holds that the property of space depends on the distribution of matter in the universe $e^{6}$. The relation between space and time is an external relation caused by the uneven occurrence of matter.

Whifehead opposes the physical theory of Einstein on epistemological grounds referring to the dilemmas of empiricism, which follows the legacy of the body-mind dualism introduced by Descartes". Through this process theory of perception, Whitehead seeks to avoid the "bifurcation of nature" that is his phrase for bodymind dualism. He hopes that bifurcation disappears since "the only events with which physics is left are the immediately sensed ones, and only possible relata for the relational theory of space and time to relate are these immediately sensed events ${ }^{\prime \prime}$. The key idea of Whitehead's phenomenal theory is the term 'event' that exists as part of nature, which is experienced by human mind as an interconnected process. The historical relation between events is treated as an internal relation. Whitehead developed the metaphysics of events as processes, later in his magnum opus Process and Reality (1929) using the fundamental notions like actual entity and prehension?.
4. Ibid, p. 175
5. Ibid, pp. 188.189.
6. Ibid, pp. 188-189.
7. Ibid, pp. 176-183.
8. Ibid, p. 189
9. Ivor Leclerc, Whitehead's Melaphysics (George Allen and Unwin Ltd, London, 1958). 
Filmer S. C. Northrop presents a critical study on Whitehead's phenomenal relational theory of space ${ }^{10}$. In his opinion, the ideas of causation and simultaneity of events are based on the contents of individual observations which essentially involve subject-object distinction. "This means that Whitehead has not succeeded in avoiding bifurcation" ${ }^{\prime \prime}$. When we define a subatomic object, even if it is in the language of process philosophy, we have to employ subject-object distinction. It appears also that, whether epistemologists and philosopher's like it or not, science requires bifurcation. ${ }^{12}$

The above points show that Whitehead's process approach is not suitable for the method of quantum physics. Science needs substance approach and subject-object distinction for conceiving cause-effect relations. Now we will focus on the further philosophical issues pertaining to quantum physics.

\section{Instrumentalism versus Scientific Realism}

The discovery of particle-wave duality of subatomic phenomena by Louise de Broglie in 1925 generated radically new questions about the realify of subatomic world. The entities like proton and electron are not 'observable' particles, because they have dual aspects of porticle and wave. This marks the collapse of Newtonian mechanistic worldview.

The present paper holds the premise that for a critical assessment of Whitehead's process philosophy, we must examine the issues raised by his phenomenal relational theory of space and time. Especially, I propose to examine the implication of the said conflict between Whitehead and Einstein to the philosophical interpretation of particle-wave duality of quantum phenomena. It can be seen that the conflict between phenomenal relational theory of Whitehead and physical relational theory of Einstein has a philosophical counter part in the conflict between Instrumentalism and Scientific Realism.

From the epistemological point of view, both phenomenal relational theory and physical relational theory follow the method of Logical Positivism. This theory of knowledge treats subatomic particles as unobservable entities, because of their

10. Filmer S. C. Northrop, Whitehead's Philosophy of Science, in Paul Arthur Schilpp (editor), The Philosophy of Alfred North Whifehead (Northwestern University, 1941), pp. 187-207.

11. Ibid, p.187

12. Ibid, pp 191-192. 
particle-wave duality and since their properties cannot be separately defined. In this situation the elementary particles of subatomic world and their properties are phrased as theoretical entities that are empirically unobservable, but have explanatory power' ${ }^{13}$.

Logical Positivism is a process theory of knowledge holding that theoretical entities form an axiomatic system, which gives meaning to the observable phenomena of subatomic world. This is called verifiability criterion of meaning. Though Logical Positivism has a proper epistemology for practical application of scientific method, it faces certain problems when examined from the ontological point of view. Ontology consists of the speculations about the real existence of fundamental entities in a static sense. For the justification of quantum physics we must resort to the ontology of theoretical entifies. Propositions of science have meaning and truth, only if the theoretical entities correspond to the fundamental aspects of physical world' ${ }^{14}$. In this situation, two different ontological positions, called Scientific Realism and Instrumentalism ${ }^{15}$, are suggested for explaining the particle-wave duality of subatomic phenomena.

\section{Instrumentalism}

Instrumentalism sticks to the process worldview in the deliberation of reality. Accordingly reality is a process (function), which allows for the multiple realisability of theoretical entities. Scientific theories, consisting of definitions of theoretical entities, are useful instruments we employ for organizing our experience of world. Theoretical entities do not represent statically existing fundamental aspects of physical reality. The phenomenal relational theory of space and time, advanced by A. N. Whitehead, is the pioneering treatise in this line of thought.

We may now refer to the competing strands under instrumentalism. Whitehead adheres to Platonic idealism in his process philosophy. An alternate thesis about subatomic process was promoted in materialist lines by Heisenberg and Bohr and it is later modified to the systems view by Fritjof Capra ${ }^{16}$. Thirdly, there is a recent development, called historical instrumentalism, due the path-breaking book of Thomas Kuhn, The Structure of Scientific Revolutions (1962).

13. Alex Rosenberg, Philosophy of Science, A Confemporary Introduction (Roulledge, London and $\mathrm{New}$ York, 2000), referred hereafter by the acronym POSCl, pp. 82.87.

14. $\mathrm{POSCl}$, p. 86

15. POSCl, pp. 91.94.

16. Fritiof Capro, The Turning Point, (Flamingo, London, 1983) 
We have to reconcile the idealist metaphysics of Whitehead with the materialist and hisłorical instrumentalism, in order to get a comprehensive vision about process reality. Instrumentalism treats the reality as an infinite process, which can be euphemistically called as void or nothingness (sunyata). It cannot talk about the existence of reality in a static manner. It fails to make any claim about the fundamental nature of human mind and world.

\section{Scientific Realism}

Scientific Realism adopts a commonsense view that theoretical entities must exist really. This argument is known as Inference to the Best Explanation ${ }^{17}$. Accordingly, the real existence of theoretical entities can be inferred as the best explanation for the predictive success of scientific laws. And, though the knowledge about those unobservable entities is an indirect one, it is frue for all practical purposes. But this view suffers from the skepticism of empiricism (David Hume). Moreover, the pluralist view of theoretical entities as really existing physically lacks any principle of unification; it ignores the mental aspect of universe. Einstein's physical relational theory of space and time adheres to scientific realism without bothering about its philosophical deficiencies.

\section{Clues for Synthesis}

As explained above, Logical Positivism and its ontological theories - instrumentalism and scientific realism - fail to provide o conclusive answer to the questions: Do theoretical entities exist really? What is the reality of physical world having particlewave duality? What is the justification of a scientific theory? Now we will find out certain innovalive arguments to solve the ontological issues.

There is no doubt that Logical Positivism is the correct method of science. The problem is with the theory of meaning and its neglect of ontology, as a consequence of the process view of logical positivism. So, in order to find the ontological status of theoretical entities, we must adopt the substance view and the content theory (representation theory or correspondence theory) of knowledge. We can talk about the existence of theoretical entities only if those concepts have representational content. So, we have to fall back to the controversy between rationalism and empiricism.

17. $\mathrm{POSCl}$, p. 91 
Immanuel Kant argued that our scientific mind consists of a rational faculty of intuition with an a priori structure of space and time ${ }^{18}$. Accordingly, theoretical entities are abstract concepts produced by scientific mind based on empirical dato. They pertain to the phenomenal world only, not to noumenon or thing-in-itself. We cannot know the reality of physical world - this view is called Kant's agnosticism. So we find that both rationalism (Kant) and empiricism. (Hume's skepticism and scientific realism) are unable to deal with the reality of theoretical entifies. Now we will inquire whether the problem can be solved by reconciling rationalism and empiricism. In this context, two doctrines of philosophy of science, namely underdetermination and folsification, will help us to advance further by modifying Kant's thesis in a revealing manner.

The doctrine of underdetermination, alternatively called as Duhem-Quine thesis, shows that experimental observation is theory-laden due to many non experimental (contextual) factors called auxiliary hypotheses ${ }^{19}$. As a result, experimental testing underdetermines scientific theor. It suggests holism about the meaning of theoretical entities; their meanings cannot be determined by logic alone. Meaning is largely a product of contextual factors, reflecting the creativity of mind. Hence, according to W.V.O. Quine, the separate criteria of truth for deduction and induction are not justified. This view leads to the conclusion that there is a 'holism about meaning' that unifies deduction and induction into an interconnected system ${ }^{20}$. The Falsification Theory proposed by Karl Popper (1902-1994) also emphasizes the mutual dependence between deductive inference and inductive inference belonging to scientific method" ${ }^{21}$.

In the light of underdetermination and falsification, we can modify Kant's rationalism and give the following postulates. There is holism about meaning of the theorefical entities; they are mutually related concepts, which have meaning as a whole. So they must represent a physical reality, which is a system of interconnected parts. In other words, the subatomic world is a system. The interconnectedness of theoretical entities as well as the relativity of space and time implies that our scientific mind is not a resenvoir of absolute ideas. It has dual features of static content and dynamic process. The ideas are static when they represent particular entities. They are dynamic

18. Immanuel Kant, Critique of Pure Reason, franslated by J.M.D. Meiklejohn (Dover Publications, Inc, Mineola, New York, 2003).

19. Alexonder Beird, Philosophy of Science, (Roulledge, London, Indian Reprint, 2003), referred hereofter by the acronym ABPOS, pp. 175-176.

20. POSCl, pp.150-153.

21. ABPOS, pp. 177-182; pp. 239-247. 
also, because they are influenced by contexts - they have history and evolution. This dualist nature of scientific mind is possible only if it has a dual structure of rational part and empirical part. .Philosophical ideas, theoretical entities, logic, mathematics, etc, are different levels (foculties) of human knowledge with rationalempirical structure. These diverse fypes of knowledge can be unified through the dualist structure of mind.

So the remaining task of scientific justification is to develop an appropriate theory of dualist reality which can account for the dual noture of human mind. When we adopt the substance view of dualist reality we must also be able to explain the fundamental aspecis of value and process in phenomenal world.

\section{The Perspective of System Philosophy}

In order to justify our scientific knowledge produced by the dualist mind, I would propose a new theory of dualist reality. This is the core of the system philosophy, which I am developing through the last several years. ${ }^{22}$ In the following paragraphs, we will see the main postulates of dualist reality and its method of justifying quantum physics.

\section{A) Phenomenal Body and Phenomenal Mind}

Through the scientific observation of natural world, we can realize that there is a hierarchy of objects which can be primarily classified into inanimate things, nonhuman living beings and human beings. They are different levels of physical body and energy. The chemical properties of atoms as well as the life and mental activities of living beings are different levels of energy. Now consider the term consciousness, which is usually regarded as synonymous with creativity, purpose and freedom. Philosophers and neuroscientists have admitted that consciousness cannot be explained by physical science which studies the material processes only ${ }^{23}$. We can adopt the evolutionary framework for natural world to propose that consciousness exists metaphysically at varying measures in all objects. Hence it is clear that the different levels of energy existing in inanimate and living things are physical reductions of levels of consciousness.

22. Luke George, Saptaloka Darshanam-Samgraham (PGL Books, Changanachery, Kerala, 2004) and the website: www.systemphilosophy.com. These publications present the original ideas of System Philosophy.

23. A.C. Groyling (ed.), Philosophy: A Guide through the Subject, (Oxford, London, 1995), p. $300-3$. 
The scientific mind through a notural process reduces phenomena into the framework of space and time and this process is called here as physicalization. This physicalization process is the same as what Kant meant by 'faculty of intuition', having the a priori structure of space and time.

I propose to adopt the ferm phenomenal mind as a synonym of metaphysical consciousness. Similarly the term phenomenal body is introduced here to denote the other metaphysical aspect, which is reduced to physical body through the physicalization process of scientific mind. Hence everything in this phenomenal universe really exists with two metaphysical aspects, namely phenomenal body and phenomenal mind. After physicalization, the scientific mind observes the thing as a combination of matter (physical body) and energy.

\section{B) System}

We realize that opposites are the dual parts of a single whole. This leads us to a Fundamental Principle of Existence: only a whole with opposite dual classes has existence. So a single property, like day or man, cannot exist alone. And, we can infer that the metaphysical relation between phenomenal body and phenomenal mind is complementarity. Phenomenal body and phenomenal mind are mutually exclusive, but they appear as dual parts of a whole, in all levels of phenomena. The term 'system' is used here to represent the complementary relation between phenomenal body and phenomenal mind in a particular thing. It shows that the hierarchy of natural world is composed of various levels of systems. Accordingly, system is the fundamental cotegory of existence which implies that the world is a union of opposites and things are always changing.

The basic system of three-dimensional world is the atom. About 110 varieties of atoms have been discovered so for. The physical concepts used to refer to the components of atom and their properties can be classified into matter part and energy part. A concept pertaining to matter part is called a particle property and that pertaining to energy part is called a wave property. So there is particle-wave duality for every component of physical atom. We will develop the philosophy of quantum physics in due course.

\section{C) Dualist Reality - Body and Mind}

Atom is the basic system and it has the dual parts called phenomenal body and phenomenal mind. These opposite properties of atom can be produced only by a reality, which has corresponding opposite parts. For convenience, I am using the terms 'Body' and 'Mind' to refer to the dual parts of reality. Hence we can define 
'Body' as the component of reality that is responsible for the material aspect of atom. Phenomenal body of atom is a finite measure of Body. Similarly, mind is defined as the mental component of reality that is responsible for the nonphysical activity (phenomenal mind or consciousness) of atom. Dualist Reality is conceived here as a system, with Body and Mind as complementary parts, according to the fundamental principle of existence.

\section{D) Model of Dualist Reality}

Next step is to explain how good and bad systems occur in this natural world. With this objective, we must see that reality exhibits the dual goals of society-interest and self-interest. By applying the fundamental principle of existence, it can be postulated that both society-interest and self-interest have positive and negative parts. Then we can equate Mind with sociely-interest and Body with self-interest. This leads to the concept of good and bad subsystems on the basis of the actions or behaviours of a system at o given point of time. Mind and Body are in a dialectical relation that can be represented by vertical straight line ( $y$-axis) and horizontal straight line $(x$ axis) respectively as in analytical geometry. Then the production function method (indifference curves) of economics is applied here to postulate the production of good subsystems in first quadrant and bad subsystems in third quadrant. This construction is termed as the Model of Dualist Reality, or '+ model' in short, and it enables us to know the values of phenomenal things.

Now there is correct answer to the question: what is good? ? Good is the positive side of the dualist goal of society-interest and self-interest. Every good intention or value - for example, love -exists with these positive dualist goals. On the contrary, bad is the negative side of society-interest and self-interest. The representation of good and bad systems in the Model of Dualist Reality shows that goodness and evil have fundamental existence, and they occur in a dialectical process. This point will lead us to the solution of the problem of evil. Good is reversed by the subsequent production of evil. Conversely, the good arises from evil, as a process of Dualist Reality.

\section{E) Human Mind and Social Systems}

The above model of dualist reality shows the process view about the evolution of natural systems in the hierarchy of inanimate things, nonhuman living beings and human beings. The epistemological problems of the materialist theory of evolution developed by Charles Darwin and followers can be solved in this system theory of evolution. 
In the case of human being as a system, the dialectics between Body and Mind has produced three levels of subsystem namely mechanical organs, mental organs (brain and nervous system), and human mind. The human mind as a subsystem has various levels of existence for the functions of life (action) and knowing. We can call these functions as organizing mind and knowing mind respectively. The knowing mind has different faculties for various types of knowledge and it is intimately related to the life-related activities of organizing mind. The functions of organizing mind produce seven social systems namely Natural Life System, Economic Life System, Political Life System, Family Life System, Ethical Life System, Artistic Life System and Religious Life System.

System philosophy of mind shows that human mind has two main levels called organizing mind and knowing mind. The organizing mind performs the activities of life in combination with physical body and these activities are organized into seven life systems as defined above.

\section{F) System Philosophy of Quantum Physics}

Scientific mind is the faculty of knowing mind, which studies natural world (Natural Life System) from the pragmatic objectives of life. It involves the physicalization process, as defined earlier. Philosophy of science deals with the structure of scientific laws and its justification. The basic problem to be tackled by philosophy of science is about the fundamental aspects of natural world. It was explained earlier that the philosophy of science pertaining to logical positivism failed to answer the question: Do theoretical entities exist really? System Philosophy answers this question as follows.

Theoretical entifies of quantum physics are physical concepts referring to the particle property and wave property of subatomic phenomena. We can reach a conclusion that Theoretical entities do not hove real existence. They are mere concepts representing the components of atom, after physical reduction. For example, quark does not really exist as a physical particle. Quark is the name given to one component of atom (a system of phenomenal body and phenomenal mind) in physical perspective. In this sense, the physical world is unreal (maya). Only systems have real existence. Physical reality is the set of theorefical entities postulated in quantum physics.

Physical reality (the set of theoretical entities) is only a metaphor denoting the physical reduction of the body-mind system called atom. Physical laws of science are not real. So there is no necessary connection in the physical cause-effect relations. The laws of Nalure are physical manifestations of the metaphysical relations between various systems of Nalural Life System (natural world). Accordingly, matter does not 
have real existence; matter is only the particle property of physical reduction of metaphysical atom. That is, matter is a theoretical entity representing various other theoretical entities like mass, extension and grovity. This ontology solves the skepticism of Kant and Hume.

Space and time are physical concepts of science. Einstein focused on the particle property of subatomic objects and showed through his Theory of Relativity that space and time are related. He dealt with the motion of bodies in space-time by defining the motion of a body in relation to another moving body as referent, instead of taking a fixed reference. That is, the bodies are in relative motion with in space-time continuum. Now it can be reasoned that space (permanence) is related to Body, while time (change) is related to Mind. That is, space-time is the concept employed to represent empirically the connection between Body and Mind at the reality level. Einstein's space-time relatively is thus confirmed philosophically.

Newtonian physics had held that space and time are absolute and independent; so matter and energy are independent entities. The source of energy (four basic forces) is external to material particles. Newton followed deism to believe that the source of energy is the transcendent God. But particle-wave duality implies that matter and energy are inter-related and they are mutually convertible as per the equation $\mathrm{e}=m c^{2}$. It meons that matter does not exist independent or external to energy. We can say: matter exists with energy; that is, matter is inherently active. Hence, matter has indeterminism or probabilistic behavior. The philosophical explanation for this property is that matter-energy is a phenomenal system. It is the physical reduction of the body-mind system at the reality level.

Quantum physics still follows the mechanistic worldview because it asserts the real existence of physical world, in which matter and energy are relative and complementary. The traditional substance philosophy - rationalism and empiricism - cannot explain the particle-wave duality and interconneciedness of subatomic phenomena. In this situation, System Philosophy treats quantum physics as a new paradigm of mechanistic worldview, holding that theoretical entities have representational content due to the physicalisation process of our scientific mind.

The particle-wave duality and the mutual convertibility of matter and energy prompted scientists like Heisenberg, Neils Bohr and Fritipo Capra to believe that the mechanistic worldview has collapsed; hence they furned to process reality for explanation of subatomic phenomena. It is materialist instrumentalism, with the assertion that only energy (field) has fundamental existence and that matter is merely a form of energy ${ }^{24}$.

24. Fritiof Capra, The Tao of Physics (Flomingo, London, $3^{\text {rs }}$ edition, 1992 1, pp. 78, 88, 223-225. 
This view is allied to Chinese mysticism. Fritjof Capra argues that subatomic, atomic and higher phenomena are caused by the self-organizing behaviour of matter. $\mathrm{He}$ treats the complementarity of matter and energy as a dynamic process of opposites, so that the sum of matter and energy is conserved in nature. We can interpret this fact as: both matter and energy have fundamental existence in interconnected manner. The adoption of process worldview with regard to matter-energy has generated many serious philosophical problems, pertaining to instrumentalism, as described above.

In the light of our model of dualist reality, we can assert that matter and energy are complementary aspects of phenomenal world, while reality is the system of body and mind. In this situation, I may propose a credible and realistic interpretation of particle-wave duality. When we see a subatomic entity as a particle, we are focusing on its materialist, static and individual existence. On the other hand, wave is a metaphor that stands for the interconnecledness of subatomic phenomena-it is the manifestation of energy. So, particle-wave or matter-energy expresses the dual aspect of permanence-change in the subatomic world.

Consider day and night, which together make a day of 24 hours. When season changes, the durations of day and night will change. This can be metaphorically stated as "a part of night is converted into day", or vice versa. Night's loss is days' gain, or vice versa. Similarly matter and energy are mutually convertible, but the sum of matter and energy is conserved in the physical world. Through the notion of complementarity, we can conclude that both matter and energy are fundamental aspects of subatomic phenomena, observed through the physical reduction of body-mind system.

Dualist reality metaphysically produces the hierarchy of systems as per the ' + model'. If we reduce the model into physical terms then space becomes the $x$-axis and time becomes the $y$-axis. In this physical model we can see the evolution of universe over time. It is interesting to note that the event of Big Bang, the origin of our universe, is the point $(0,0)$ when the Model of Dualist Reality is reduced to the physical coordinates of space-time. Hence, Big Bang is not a real event. It is a construction of our scientific mind - it is the scientific description of the origin of our physical universe.

Finally, consider the meaning of the phrase scientific reality, which is the vision of reality entertained by scientists. Scientific Reality must overcome the problems of the conflicting doctrines of Intelligent Design and Atheism (materialism). System Philosophy asserts that Intelligent Design (the mental aspect of world representing its purpose) is in dialectical relation with the material part. So we need the 
reconciliation of Intelligent Design and Materialism. The ' + model' of Dualist Reality achieves this objective by treating Intelligent Design (Mind) as $y$-axis and Body as $x$-axis. Hence scientific reality is a system of Intelligent Design and Body, with the principle of complementarity.

\section{Conclusion}

This orticle has developed a method for reconciling the difference between Whitehead and Einstein regarding space-time relativily. It is achieved by synthesizing instrumentalism and scientific realism through the model of dualist reality under System Philosophy. This innovative vision articulates the substance ontology in evolutionary system perspective. Adopting the representational (content) theory of knowledge, System Philosophy elucidates that the theoretical entities pertaining to particle-wave dualily are justified by the real existence of Natural life System, which is a combination of phenomenal body and phenomenal mind.

\section{References}

1. A.C. Grayling (Editor), Philosophy: A Guide through the Subject, London: Oxford Universily Press, 1995.

2. Alexander Beird, Philosophy of Science, London: Roulledge, Indion Reprint, 2003.

3. Alex Rosenberg, Philosophy of Science, A Confemporary Iniroduction London: Routledge, 2000.

4. Friljof Capra, The Turning Point, London: Flamingo, 1983.

5. Fritiof Capra, The Tao of Physics, London: Flamingo, $3^{\text {rd }}$ edition, 1992.

6. Immanuel Kant, Crifique of Pure Reason, translated by J.M.D. Meiklejohn, New York: Dover Publications, Inc, Mineola, 2003.

7. Ivor Leclerc, Whitehead's Metophysics, London: George Allen and Unwin Ltd, 1958.

8. Luke George, Saplaloko Darshanam-Samgraham, Changanachery, Keralo: PGL Books, 2004, and the website: www.systemphilosophy.com.

9. Paul Arthur Schilop (Ed.), The Philosophy of Alfed North Whiteheod New York: Northwestern University, 1941.

10. Poul F. Schmid, Perception and Cosmology in Whileheod's Philosophy, New Jersey: Rutgers University Press, 1967.

11. Robert John Russell (Ed.), Fifly years in Science ond Religion - Ian G. Barbour and his Legacy, England and USA: Ashgate Publishing Ltd, 2004. 